\title{
Obesogenic and histopathological effect of monosodium glutamate on the adrenal gland of maternal and postnatal albino rats
}

\author{
Fatma Alzhraa Fouad Abdelbaky*, Heba Hassan AbdallahAbdelmougod, Nabil Abdel Kader Hasan and Abdel \\ Hamid Sayed AboBakr Ali \\ Anatomy department, Faculty of medicine, Minia university. \\ *Corresponding author: fatoma76@yahoo.com ;Tel: +01006204663.
}

\section{Article information}

Received: 22 April2021

Revised: 16 May2021

Accepted: 26 May 2021

\section{Key words}

Monosodium glutamate

Adrenal gland

Pups

Masson trichrom

\begin{abstract}
Monosodium glutamate (MSG) is a flavoring food additive that's found in many foods like chips, and fast foods.

The aim of this study was to demonstrate the injurious effects of MSG on the adrenal glands of the female albino rats and its potentiality to cross the placental barrier carrying its injurious effects to their pups.

Twenty-five female albino rats weighing about (200) $\mathrm{g}$ were mated then separated into two groups. The control group (10 rats),and MSG-treated Group(15 rats) received $10 \mathrm{~g} / \mathrm{kg}$ MSG orally, dissolved in water at a concentration of $10 \mathrm{~g} / 100 \mathrm{ml}$, starting on day 7 to 20 day of gestation.A day after delivery, animals were weighed, blood samples collected then sacrificed, and the adrenals were collected and examined by the light and electron microscope.

Statistically, there was a significant increase in the body weight and decrease in adrenal weight of MSG-treated mothers and their pups, as well as a decrease in the corticosterone level in MSG-treated mothers.

Histologically, MSG-treated mothers and pups showed many degenerative changes, with thinning of the capsule that was confirmed by Masson trichrome stain, a abnormal structure of Zona Golmeruloza and Zona Fasciculata, and areas of shedding and blood vessels were noticed. Shrunken nuclei and degenerated mitochondria with disrupted cristae and penetration of the lipid droplets to form "myelin-like" structures were noticed by E/M examination.

The study concluded that MSG had an unwholesome effect on the structure of the adrenal tissue of both pregnant rats and their pups.
\end{abstract}

\section{Introduction}

Monosodium glutamate (MSG )is a food additive that is widespread used as a flavor enhancer. It dissociatesin an aqueous solution releasing free glutamate elicitinga unique umami taste, responsible for the positive effect of MSG on the palatability of food(1\&2).

The consumption of MSG has increased all over the world in recent years with an average daily intake from foods reported to be about up to $1 \mathrm{~g}$ in Europe, $4 \mathrm{~g}$ in Asian countries, and $10 \mathrm{~g}$ in Germany (3). It has many trade names such as Ajinomoto, Chinese salt, and E621(4)and according to (5), it may be present in packaged foods without appearing on the label.

(An experiment stated that overconsumption of MSG resulted in a complex of symptoms termed 'Chinese restaurant syndrome', including weakness, numbness, skin flushing, sweating, dizziness, and headaches(6). Moreover, many studies proved the damaging effect of MSG excess use on multiple body organs, such as neurotoxic effects on the cerebellum (7),damage of both exocrine and endocrine cells of the pancreas (8). Also, steatohepatitis and preneoplastic changes in the liver (9). furthermore, varyingdegrees of cytoarchitectural distortion of the kidney were reported with prolonged MSG consumption (10).Also,() another study reported that the responsiveness of the hypothalamic-pituitary-adrenal (HPA) axis could be impaired with chronic MSG administration(11). By using
$[3 \mathrm{H}]$ glutamic acid as a tracer, MSG was also shown to cross the placental barrier and to distribute to embryonic tissues(12).

This study iaimed to ascertain the obesogenic effect of MSG administration and its toxic effects on the histological structure of the adrenal gland of the maternal and postnatal albino rats.

\section{Material and methods \\ Experimental animals:}

The study was conducted on 25female albino rats, weighing $200 \pm 5 \mathrm{~g}$. The rats were mated with males resulting in pregnancies that were detected by daily vaginal smears, after a positive smear the rats were transferred into separate, clean, properly ventilated plastic cages and given regular diet and water under controlled conditions. The experiment was approved by the Ethical Committee for research work at Minia University.

MSG was purchased from DØBELLA Food and Beverage and from Mega foods, Minia, Egypt with purity up to $99 \%$, It was in the form of white crystals.

\section{Experimental design:}

The Rats were divided into two groups as follows: 
Group I (control group):It included 10 rats, that were held without medication throughout the experiment.

Group II (MSG treated group):It included 15 rats, each received a daily dose of $10 \mathrm{~g} / \mathrm{kg}$ MSG which was given orally, by dissolving it in the drinking water at a concentration of $10 \mathrm{~g} / 100$ $\mathrm{ml}$ water(13).The MSG treatment began on day 7 of gestation and continued till day 20 (one day before delivery of the litters).

\section{Methods:}

Rats of both groups were weighted at the start of the experiment and just before sacrificing. Within 24 hrs. of birth the pups born to control (untreated) and MSG-treated mothers were counted and weighed. Blood samples were collected from the mothers, then together with their pups they were sacrificed by cervical dislocation and via median laparotomy with careful dissection of the structures.The right adrenal glands were collected then dissected carefully from the associated adipose tissue, weighed,and blotted on a filter paper then cut to sagittal sections.

\section{Histological examination:}

The specimens of the adrenal glands of different groups weresplit into two groups to be subjected to the following preparations:

The first group was fixed in $10 \%$ neutral buffered formaldehyde solution at room temperature for $24 \mathrm{hrs}$. To harden and preserve the tissues and protect them against subsequent processing steps. Following fixation, specimens in labeled cassettes were dehydrated in ascending grades of ethyl alcohol until pure, water-free alcohol is reached. Then cleared by xylene, embedded in paraffin, and sections were cut at $5 \mu \mathrm{m}$ thickness by Microm HM 315microtome then spread on warm water and fixed by egg albumin on slides(14).Sections were stained with either hematoxylin and eosin (H\&E)or Masson Trichrome staining. Tissue sections were examined and images were captured using Olympus digital camera on Olympus light microscopy (Olympus, Japan).

The other group of sections was fixed in 5\% glutaraldehyde for $24 \mathrm{hrs}$. Then washed three times in cacodylate buffer, fixed in $1 \%$ osmium tetroxide then washed again in the buffer. Dehydration was carried out using ascending grades of ethanol. Then they were cleared in propylene oxide and placed in propylene oxide: Epon-Araldite formulation (1:1) overnight, then embedded in Epon 812 using a gelatin capsule. The samples were polymerized and semi-thin sections $(0.5-1 \mu \mathrm{m})$ were done using an LKB ultramicrotome,then stained with $2 \%$ aqueous toluidine blue. Ultrathin sections $(50-80 \mathrm{~nm})$ from selected areas of trimmed blocks were prepared. The ultrathin sections were examined using an electron microscope 'Jeol JEM 1010' (Japan) at the electron microscopic unit in Assiut university.

\section{Statistical analysis}

The results are illustrated as the mean \pm standered deviation(M \pm SD. The data analysis was performed using SPSS version 22.0 for Windows (IBM, Chicago, IL). Normality of distribution was determined by the Shapiro-Wilk test in the case of the mothers (as the sample number was less than 50) and KolmogorovSmirnov test in the case of the pups (as the sample number was more than 50) where $\mathrm{p}$ values of more than $5 \%$ indicate a normally distributed data. Followed by the Independent sample T-test for the significance of the parametric quantitative data between the two groups. Values of $p \leq 0.05$ were considered statistically significant.

\section{Results}

1) Rat body and adrenal weight study(table 1, histograms 1-4):

Before sacrificing the rats, their body weights were measured. There was a significant increase in the total body weights of the MSG-treated mothers when compared to that of the control group $(\mathrm{P}<0.001)$. $\quad(\mathrm{M} \pm \mathrm{SD})$ of the body weights were $(229.9 \pm 9.5)$ in the control group, $(259.9 \pm 16.5)$ in MSG treated group, this was also the case when comparing the weights of the pups of both groups, $(\mathrm{M} \pm \mathrm{SD})$ of their body weights were (7.2 \pm 0.7$)$ in the control group, $(8.8 \pm 2)$ in the pups of MSG treated mothers. This increase was highly significant $(\mathrm{P}<0.001)$.

After sacrifice, the adrenal glands of each group were weighted by Sartorius balance. The $(\mathrm{M} \pm \mathrm{SD})$ of weight of adrenal of control mothers were $(33.4 \pm 2.6),(2.2 \pm 0.7)$ in their pups, $(26.8 \pm 4.3)$ in MSG treated mothers, and $(1.4 \pm 0.6)$ in their pups.This difference was found to be significant $(\mathrm{P}<0.001)$.

\section{2) Biochemical study(table 1, histogram 5):}

The serum level of cortisol was measured in blood samples of the mothers of each group. The results showed that the administration of MSG significantly decreased serum cortisol levels compared to the control group $(\mathrm{P}<0.001)$. $(\mathrm{M} \pm \mathrm{SD})$ of cortisol level in control motherswas $(0.94 \pm 0.19)$, and cortisol level wae $(0.64 \pm 0.1)$ in the MSG-treated mothers.

Table (1): Showing different statistics represented by $\mathrm{M} \pm \mathrm{SD}$ and the significance of these differences (P Value) between groups.

\begin{tabular}{|l||l||l||c|}
\hline Groups & Montrol group & $\begin{array}{l}\text { MSG treated } \\
\text { Group M } \pm \text { SD }\end{array}$ & P-Value \\
\hline $\begin{array}{l}\text { Body weight of the } \\
\text { mothers (g) }\end{array}$ & $229.9 \pm 9.5$ & $259.9 \pm 16.5$ & $<0.001$ \\
\hline $\begin{array}{l}\text { Body weight of the } \\
\text { pups (g) }\end{array}$ & $7.2 \pm 0.7$ & $8.8 \pm 2$ & $<0.001$ \\
\hline $\begin{array}{l}\text { Adrenal gland weight } \\
\text { in Maternal } \\
\text { groups(mg) }\end{array}$ & $33.4 \pm 2.6$ & $26.8 \pm 4.3$ & $<0.001$ \\
\hline $\begin{array}{l}\text { Adrenal gland weight } \\
\text { in the pups (mg) }\end{array}$ & $2.2 \pm 0.7$ & $1.4 \pm 0.6$ & $<0.001$ \\
\hline \hline $\begin{array}{l}\text { Cortisol level in } \\
\text { maternal groups } \\
\text { ( } \mu \text { g/dl) }\end{array}$ & $0.94 \pm 0.19$ & $0.64 \pm 0.1$ & $<0.001$ \\
\hline \hline
\end{tabular}




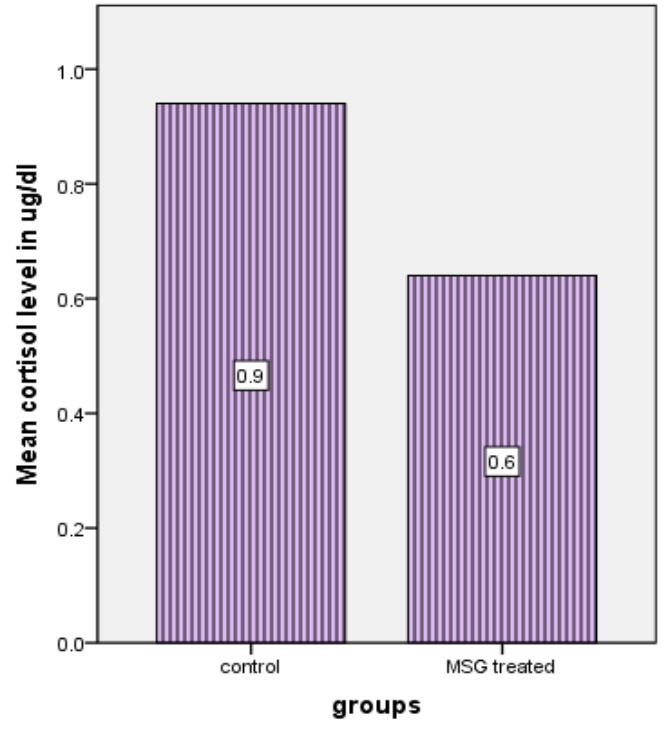

Histogram (5): Showing the mean serum corticosterone level in control and MSG treated mothers.
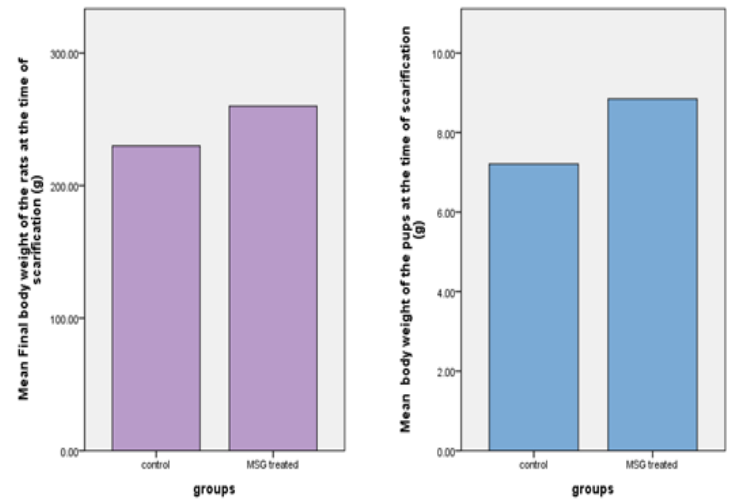

Histograms (1,2): Showing mean body weights in different studied groups.
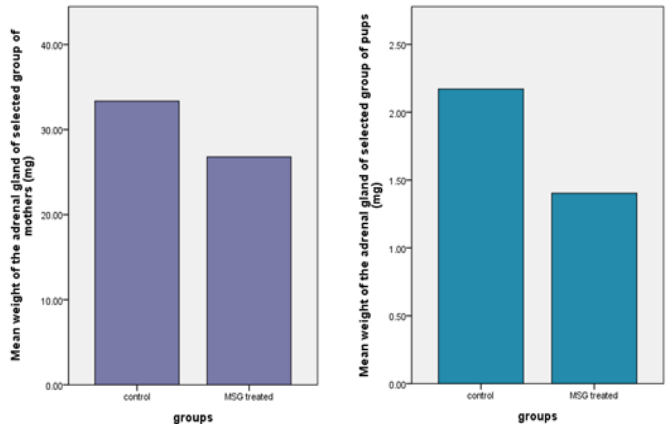

Histograms $(3,4)$ : Showing mean adrenal weight in different studied groups.

\section{3)Histological studies:}

A) Light microscopic studies:

-Histological study using hematoxylin and eosin.

The adrenal sections of the control mothers group showed normal histological structure as the outer zoned cortex and inner medulla encased by a connective tissue capsule. Beneaththe capsule, the cortex was subdivided into three zones; zona golumeruluza $(\mathrm{ZG})$, zona fasciculate $(\mathrm{ZF})$, and zona reticularis (ZR). The peripheral thin ZG contained small nests of cells with little cytoplasm. The cells of the subjacent ZF appeared arranged in cords and appeared large polyhedral in shape with acidophilic lipidized cytoplasm and large rounded nuclei. The clear cells of the ZF were merged with the underlying ZR, which had a deeper eosinophilic and less lipidized cytoplasm. Blood sinusoids lined with the flat endothelial cells appeared surrounding the cellular nests and separating the cords. The inner core medulla was fairly homogeneous and composed of large, polygonal, epithelial cells surrounded by blood sinusoids (Figs.1 and 2).

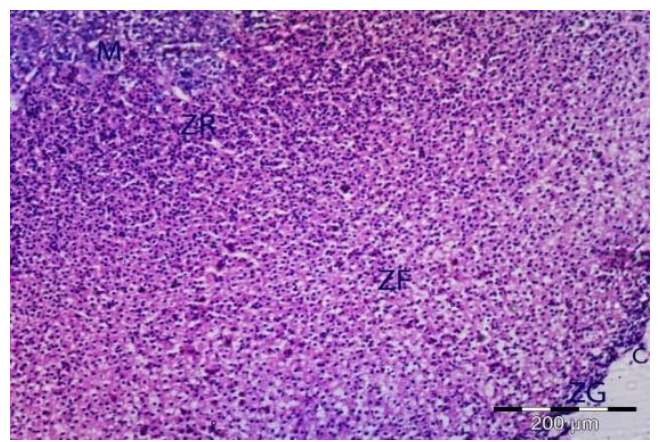

Fig (1): A photo-micrograph of a section of a control mother's Adrenal gland, showing typical encapsulated (c) gland structure with outer cortex and inner medulla (M). The cortex is further divided into subcapsular ZG, followed by ZF which is the widest of all zones, and a subjacent ZR surrounding the adrenal medulla present at the core of the gland. (H\&E X250)
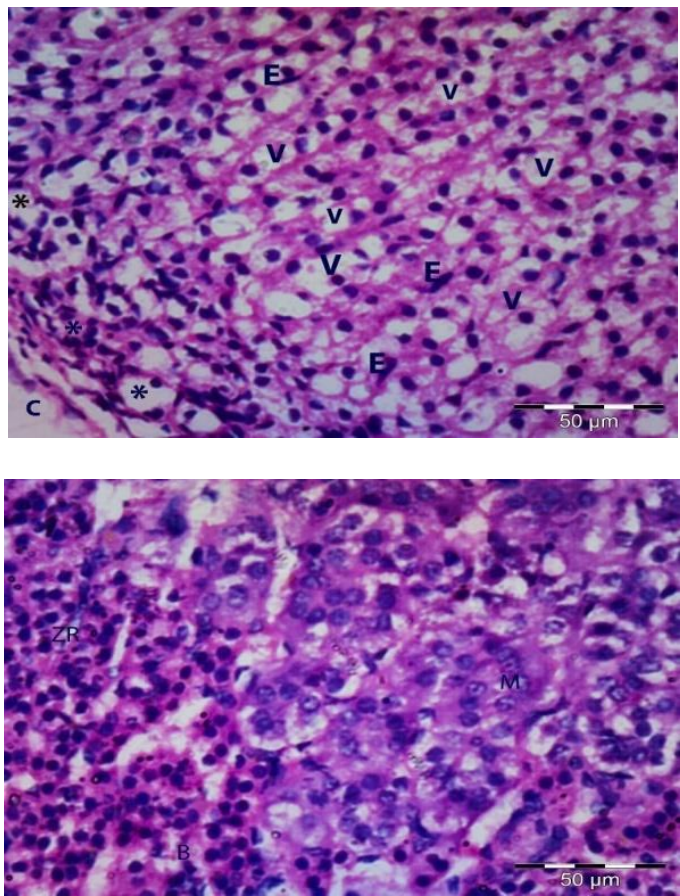

Fig (2): photo-micrographs of a section in the adrenal gland of a control mother showing (I) the capsule of the gland (C) and beneath it is the adrenocortical zones. The subcapsular thin glomerulosa zone is formed of small nests of cells $(*)$.Followed by the ZF with its characteristic cordal pattern and which cells show a large rounded nucleus and a lipid-rich vacuolated cytoplasm (V). (II) the ZR at the right side of the photo, which has more eosinophilic and less lipidized cytoplasm, Followed by the adrenal medulla (M) showing medullary cells arranged in small nests and cords with amphophilic to 
basophilic cytoplasm and indefinite cytoplasmic membranes, vesicular nuclei (arrows). (Cords and nests are demarcated by dotted lines and circles)

Blood sinusoids (B) lined with endothelial cells (E) were also found among the gland. (H\&E X400)

On the other hand, the adrenal sections of the MSG-treated mothers showed many degenerative changes, with apparent thinning of the capsule and a disorganized structure of the $\mathrm{ZG}$ and ZF. The ZG cells appeared crammed with multiple intercellular spaces whereas most of the ZF cells were swollen with an increased foamy appearance in some partitions and loss of it in others, apparent loss of the cord-like architecture was noticed. Some cells of these layers showed karyolitic nuclei, while others lost their nuclei. Few cells partially lost their cellular membranes. Dilated blood sinusoids with interstitial congestion in the ZR and medulla were noticed (Figs 3-4).

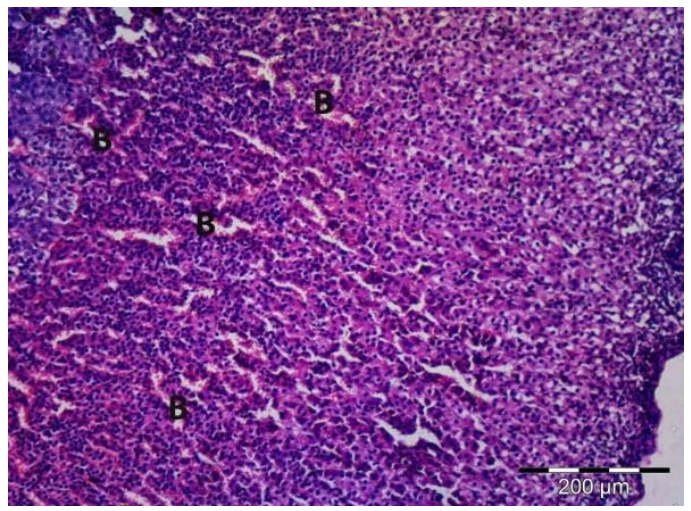

Fig (3): A photo-micrograph of an adrenal section in MSG treated mother showing the same general outline yet with disorganized architecture of ZG and $\mathrm{ZF}$ with increased $\mathrm{ZF}$ thickness at the expense of the $\mathrm{ZG}$ and the capsule which are thinned. The regular structure of the ZR and the adrenal medulla was noticed with dilated congested blood sinusoids all over the gland (B). (H\&E X250)
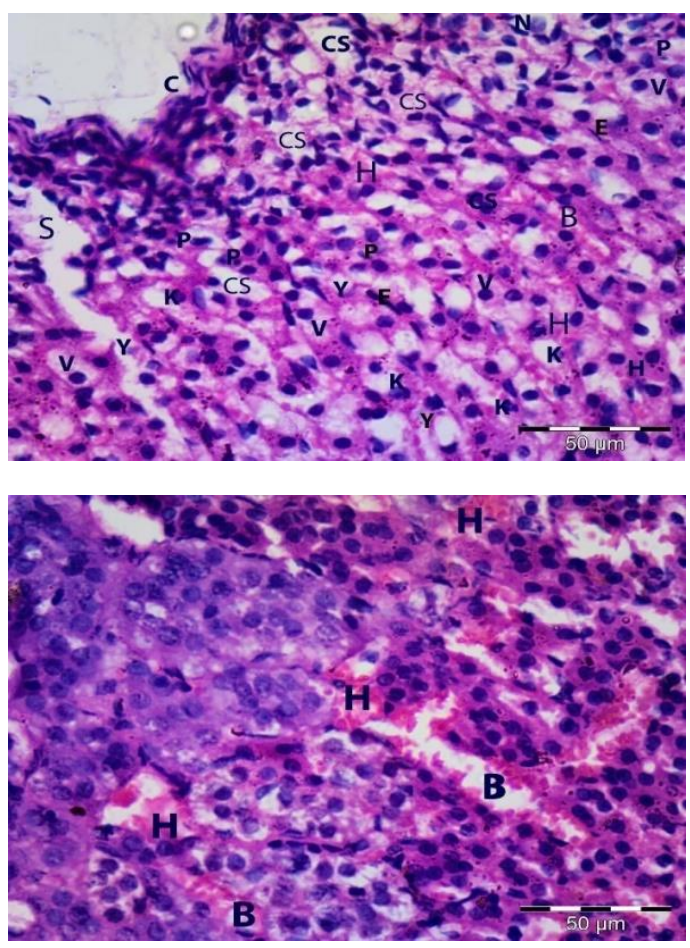

Figs (4): photo-micrographs of a section of the adrenal gland of MSG treated mother showing (I) apparent thinning of the capsule (C) and a disorganized architecture of the ZG and ZF, with loss of the cordal pattern of the latter. Cells of the ZF ranged between areas of increased vacuolation (V) to areas of non- vacuolated crowded cells with collapsed sinusoids lined by endothelium (E) in between them. Some cells lost their cellular membranes and cytoplasmic syncytium (CS) was formed between them. Some cells showed nuclear pycnosis $(\mathrm{P})$, Karyorrhexis $(\mathrm{K})$, or karyolysis $(\mathrm{Y})$. Sites of cellular shedding $(\mathrm{S})$ were noticed. Neutrophil Infiltration $(\mathrm{N})$ was also noticed (II) The adrenal medullary cells with the surrounding ZR were less affected. Yet, hypervascularity (B) with areas of interstitial hemorrhage $(\mathrm{H})$ was more obvious at this zone. (H\&E X400)

The sections of the control pups showed that the zonation of the gland was almost established. The cells of the cortex were large with eosinophilic cytoplasm arranged in three zones. A thin connective tissue capsule enveloped the gland tissue. The ZG was thinner than the adult rats and had a small round or elongated cells with scarce cytoplasm. The ZF was composed of cords of big round cells with abundant cytoplasm. The remaining cortex was occupied by haphazard cords of cells, similar to those seen in the ZF yet with a more irregular shape and arrangement and with fewer lipid droplets, and is referred to as zona juxtamedullaris as it does not present the regular network arrangement of the adult zona reticularis. Irregular clusters of small medullary cells with deeply staining nuclei were seen within the center of the gland ( Figs 5,6,).

The sections of the pups of the MSG treated group showed multiple areas of cellular shedding with a more congested gland core ( Figs 7,8).
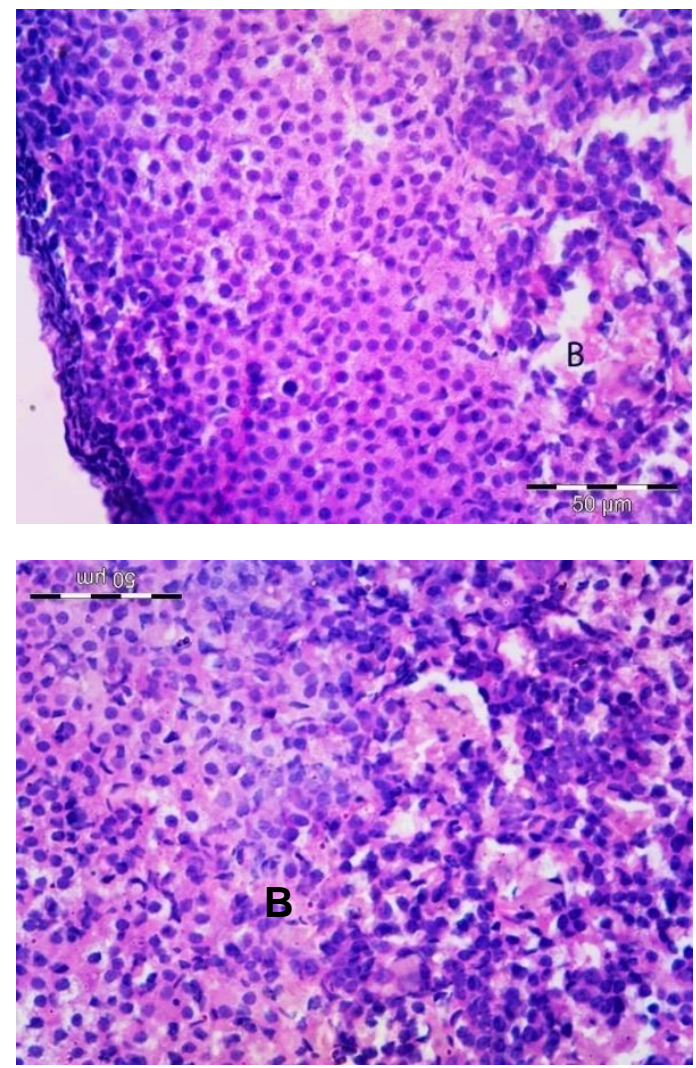

Figs (6): photo-micrographs of a section of the adrenal gland of a control pup showing that the cortex is dominated by large eosinophilic cells arranged in the cortical zones with prominent vascularity (B) in the growing gland. Medullary Clusters with deeply staining nuclei are seen aggregating together within the center of the gland. (H\&E X400) 


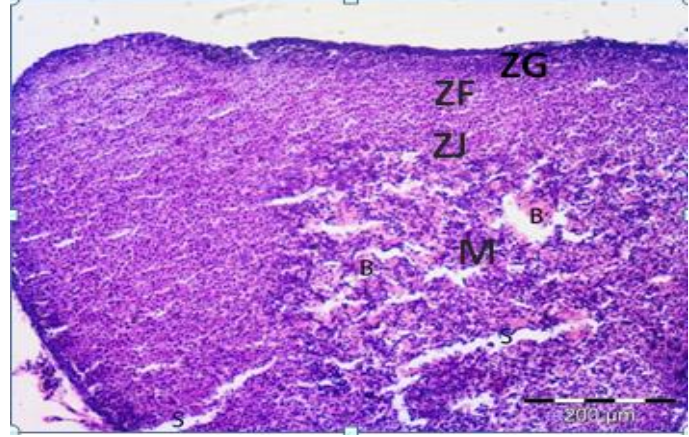

Fig (7): A photo-micrographs of sections of the adrenal glands of a group II pups showing the same general architecture as an outer capsule followed by a zoned cortex with a medullary core, the gland appeared to be more congested (B) with multiple areas of shedding (S). (H\&E X250)

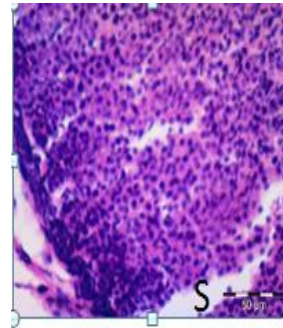

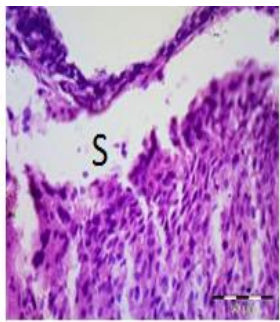

॥

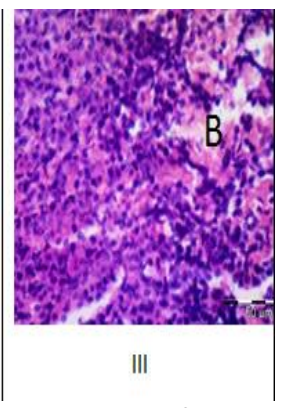

III
Figs (8): photo-micrographs of a section of the adrenal gland of an MSG treated pup showing (I-II) Multiple areas of shedding (S) within the cortical layers in addition to capsular separation. (III) Dilated congested vessels (B) that's more obvious within the gland core. (H\&E X400)

\section{Histological study using Masson's trichrome.}

Masson's Trichrome stained sections showed an apparent decrease in the collagen fibers of the capsule in the MSG treated mothers and their pups in contrast to the thick regular fibers of the control group sections ( Figs 9-12).

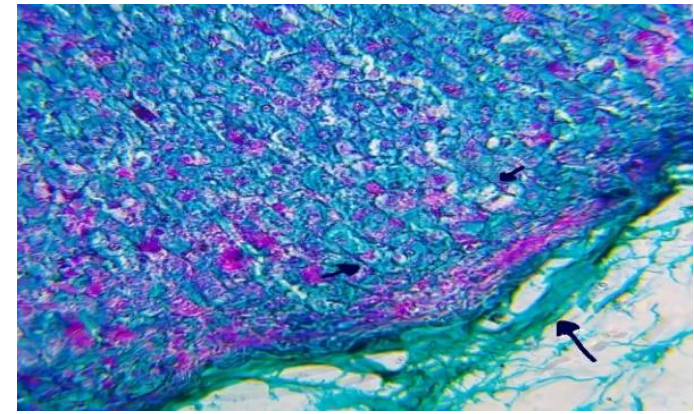

Fig (9): A photo-micrograph of a section of the adrenal cortex of a control mother, showing thick collagen fibers of the capsule and regular glandular architecture.(Masson's trichrome X400)

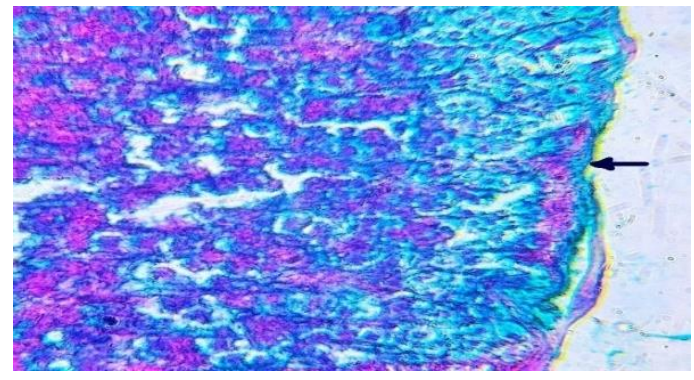

Fig (10): A photo-micrograph of a section of the adrenal cortex of MSG treated mother, showing obvious decrease in the collagen fibers of the capsule with irregular trabeculae and cellular outline.(Masson's trichrome X400)

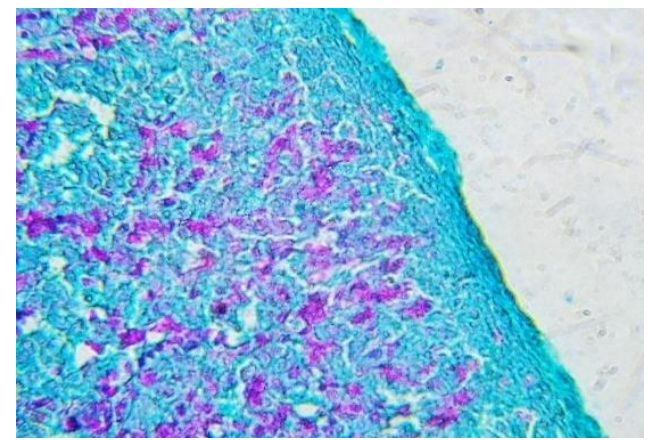

Fig (12): A photo-micrograph of a section of the adrenal cortex of a control pup, showing thick capsular fibers. (Masson's trichrome X400)

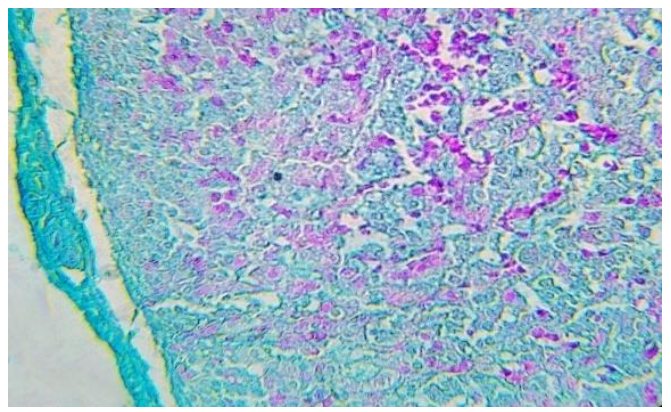

Fig (13): A photo-micrograph of a section of the adrenal cortex of a pup of MSG treated mother, showing a feeble capsule that's separated from the gland with a decrease in its collagen fibers.(Masson's trichrome X400)

\section{B) Ultrastructural study:}

Ultrastructural examination of the adrenal gland of the control mothers revealed that the cells of the cortex contained normal euchromatic nuclei and many mitochondria in addition to lipid droplets of various densities and sizes seen in the cytoplasm. The medullary cells contained ovoid nuclei with irregularly dispersed chromatin, and secretory granules including norepinephrine granules which content was electron dense that's often eccentrically located, and epinephrine granules which content was of variable electron-density and filled most of the sacs. ( Figs 13,14)
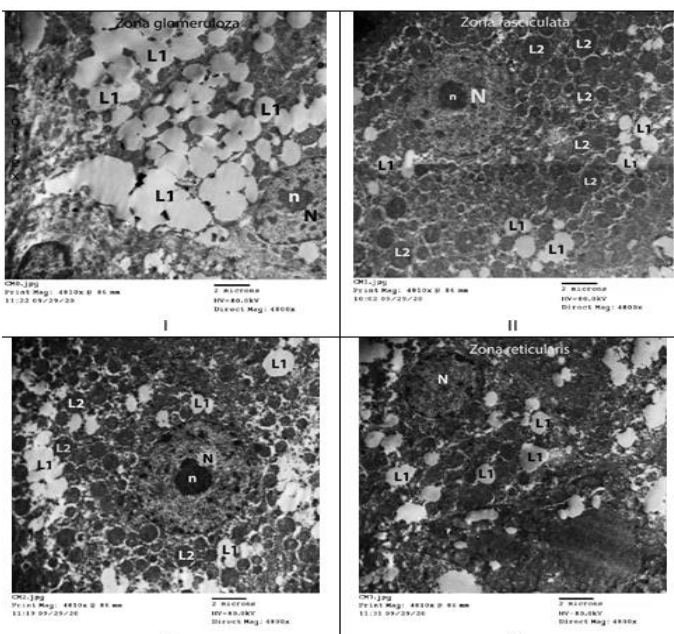
Figs (13): Transmission electron microscopy (TEM) of an ultrathin section in the adrenal cortex of a control mother showing cells of the three zones having euchromatic nuclei (N) with central nucleoli ( $\mathrm{n}$ ) and patches of heterochromatin. The cytoplasm having lipid droplets of various densities; electron-lucent (L1) and electron-dense (L2) droplets, full of secretory material which are more numerous in the ZF \&ZRcells (II, III, IV. ) $(\times 4800)$

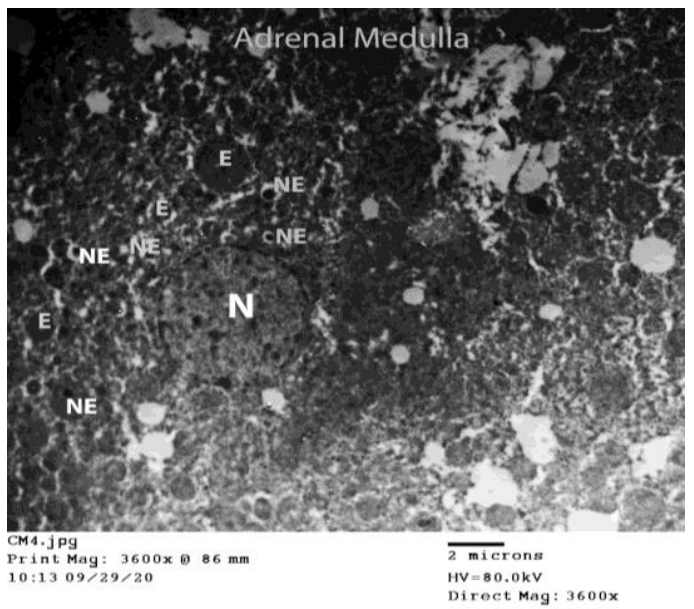

Fig (14): TEM of an ultrathin section in the adrenal medulla of a control mother showing a medullary cell with secretory granules including norepinephrine granules (NE) whose content is electron-dense and eccentrically located, and epinephrine granules (E) which have a variable electron-dense content that fills most of the sacs. $(\times 3600)$

In MSG treated mothers mothers, the ultrastructural examination of the adrenal cells revealed different degenerative stages. Shrunken nuclei in some cortical cells surrounded by a perinuclear electron-lucent zone, or with an indentation in the nuclear membrane. Some cells had pyknotic nuclei with irregular nuclear envelopes and condensed peripheral heterochromatin. The ZG cells displayed a marked increase in lipid deposition throughout the cytoplasm. Also, ZF showed many lipid droplets; some of them were full while few exhibited depletions of the secretory material. Degenerated and vacuolated mitochondria with disrupted cristae were seen. Widening in the cellular junction between cells, disruption of cellular membranes, necrotic cells in various stages of degeneration, and resorption zones with the presence of hemorrhage were also recognized.

The medullary cells appeared less affected than the cortical cells, however, the cytoplasm was engorged with chromaffin granules, and some degenerated mitochondria were noticed ( Figs 15-19).

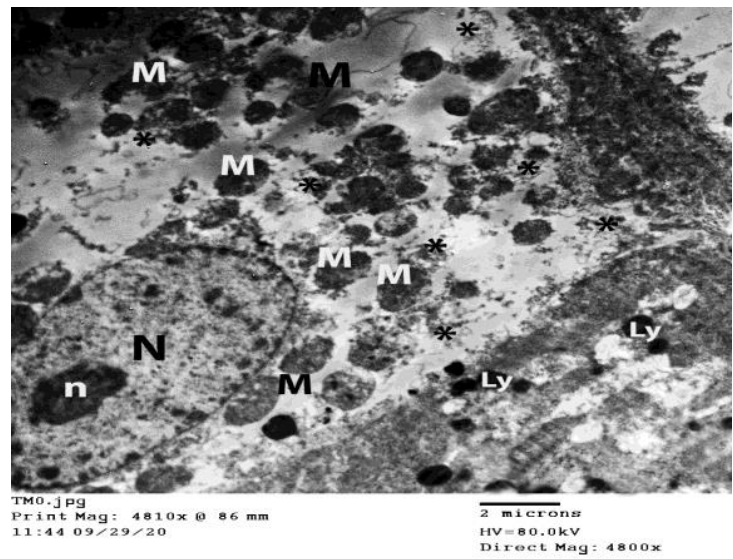

Fig (15): TEM of an ultrathin section in the adrenal gland of a treated mother showing a ZG cell containing swollen mitochondria (M) with disrupted cristae mitochondria with lipid-like inclusions, and breakthrough of some mitochondria into lipid droplets to form "myelin-like" structures $\left({ }^{*}\right)$ as noticed. Multiple lysosomes (Ly) dispersed within the cell. $(\times 4800)$

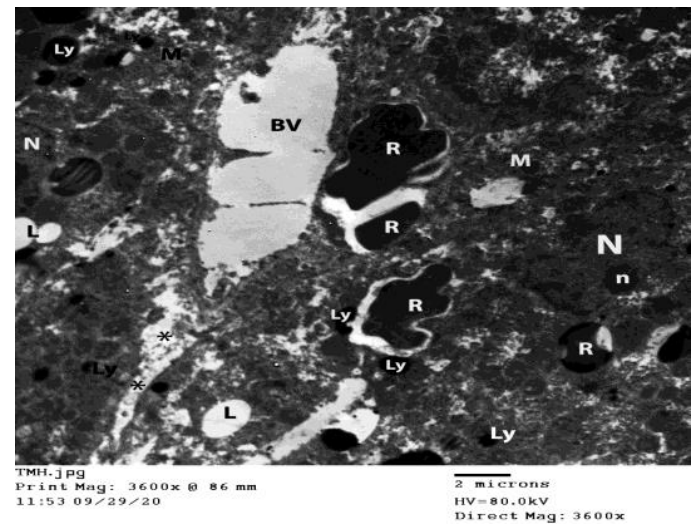

Fig (16): TEM of an ultrathin section in the adrenal cortex of a treated mother showing a cell of the ZF with an irregular-shaped nucleus $(N)$ with eccentrically located nucleolus ( $n$ ). Heterochromatin in the form of lumps condensed mainly near the inner side of the nuclear membrane.Widening in the cellular junction between cells $\left({ }^{*}\right)$ with the presence of hemorrhage (RBC's (R)). Lysosomes (Ly) of different sizes and few electron-lucent lipid droplets $(L)$ are seen within the cytoplasm.

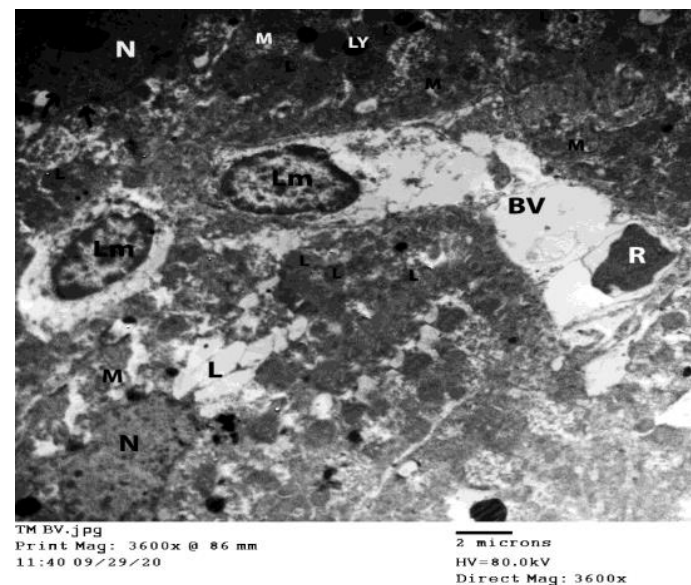

Fig (17): TEM of an ultrathin section in the adrenal gland of a treated mother The upper right side showing a ZR cell with an indented nucleus (arrows), while the lower rt side containing a shrunken nucleus $(N)$ with an irregular nuclear membrane. The cytoplasm shows lipid droplets of variable sizes $((L)$ and electron-densities, swollen destructed mitochondria (M), and few lysosomes (Ly). Lymphocytes (Lm) are noticed within a gland vessel (BV) and infiltrating the gland. Notice $\mathrm{Rbc}(\mathrm{R})(\times 3600)$

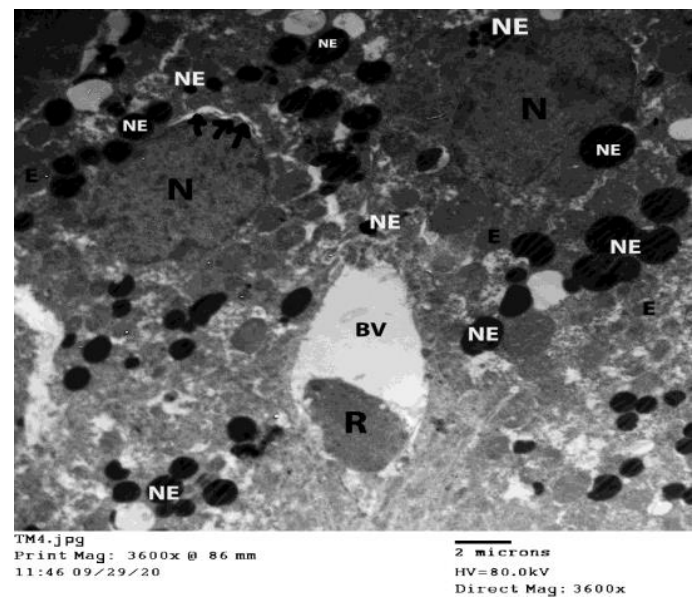

Fig (18): TEM of an ultrathin section in the adrenal gland of a treated mother showing medullary cells with the characteristic chromaffin granules $(E, N E)$ and 
oval nuclei with irregularly dispersed chromatin, a shrunken nucleus with a perinuclear electron-lucent area (arrows) is seen. Swollen mitochondria with disrupted cristae. $(x 3600)$

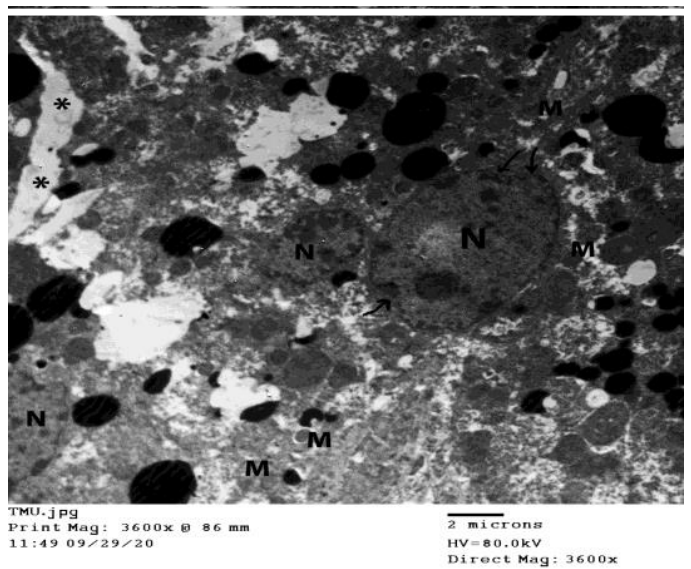

Fi j (19): TEM of an ultrathin section in the adrenal gland of a treated $m$ sther showing a medullary cell with two unequal nuclei (N) showing indented nuclear membranes (arrows), Swollen disrupted mitochondria (M), and widened cellular junction $\left({ }^{*}\right)$ between it and the neighboring cell.(x3600)

The ultrathin sections of the control pups showed ZG cells with irregularly round or elongated cell nuclei that contained one or two nucleoli and had small patches of heterochromatin. The cytoplasm wasscanty with few lipid droplets of a moderate electron-dense matrix, dispersed organelles, and circular or elongated mitochondria with tubular cristae. ZF cells were rounded with a rounded nucleus containing heterochromatin which was more at the nuclear periphery and plentiful cytoplasm containing numerous mitochondria and lipid droplets. Zona juxtamedullaris cells were irregularly rounded with the nucleus containing tiny patches of heterochromatin and the cytoplasm containing scarce Lipid droplets and round mitochondria with dark matrix and vesicular cristae. Medullary cells were polymorphic with oval nuclei that contained a prominent nucleolus. The cytoplasm had abundant mitochondria with lamellar cristae and sparse catecholamine storage granules ( Fig 20).
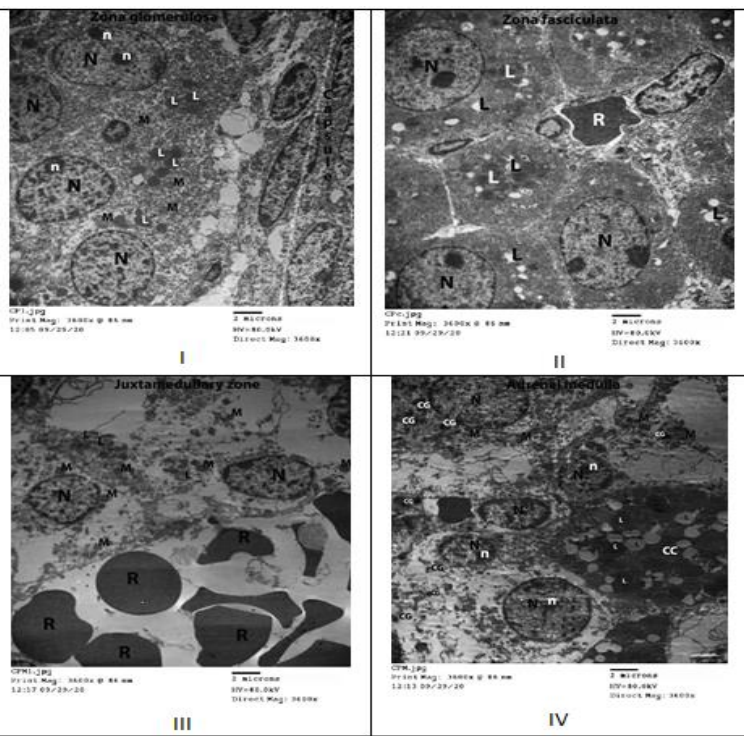

Figs (20): TEM of an ultrathin section in the adrenal gland of a control pup showing (I) ZG cells with round or elongated nuclei (N) containing one or two nucleoli ( $n$ ), and scanty cytoplasm containing mitochondria (M) with tubular cristae, dispersed organelles and few lipid droplets (L). (II) ZF cells with round nuclei containing heterochromatin at the nuclear periphery and abundant cytoplasm containing numerous mitochondria and lipid droplets. (III) Zona juxtamedullaris cells with nuclei containing tiny patches of heterochromatin and the cytoplasm containing scarce Lipid droplets and round mitochondria of a dense matrix. (IV) Polymorphic medullary cells with oval nuclei that contained prominent nucleoli and heterochromatin patches, abundant mitochondria with lamellar cristae, and sparse catecholamine storage granules. Cortical cell (CC) is seen among medullary ones. Blood sinusoids filled with RBCs $(R)$ are also seen among the gland. $(\times 3600)$

In MSG treated pups, the ultrastructural examination of the adrenal sections revealedthat the cells had euchromatic nuclei with decreased heterochromatin material. Some cells had shrunken nuclei with irregular or indented nuclear envelopes. Swollen mitochondria with disrupted cristae were noticed with penetration of some mitochondria of the ZG cells into the lipid droplets forming a myelin-like structure. Increase in the secretory material of the ZF cells and chromaffin granules in medullary cells was obvious. Areas of congestion with the presence of erythroblasts within the gland were also noticed. (Fig 21).
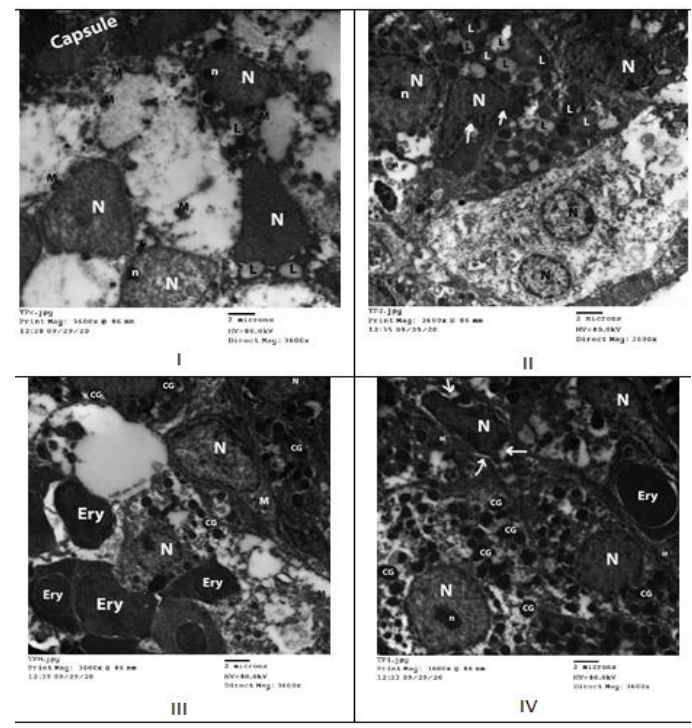

Figs (21): TEM of an ultrathin section in the adrenal gland of agroup II pupshowing different cortical and medullary cells having euchromatic nuclei (N) with single or absent nucleoli $(n)$ and with decreased heterochromatin material. Cells having shrunken nuclei with irregular or indented nuclear membranes (white arrows) are seen. Swollen mitochondria (M) with disrupted cristae is noticed with penetration of some mitochondria into the lipid droplets forming myelin-like structure $\left({ }^{*}\right)$ in the ZG cells (I). Increase in the secretory material of the cells as lipid droplets (L) in ZF cells (II) and chromaffin granules (CG) in medullary cells (IV). Areas of hemorrhage with the presence of erythroblasts (Ery) within the gland are noticed (III, IV). A binucleated cell with common cytoplasm and disrupted organelles is seen (II). (×3600).

\section{Discussion:}

Food additives like monosodium glutamate (MSG) are used widely and excessively regardless of the bad reputation it is getting overtime. There is no disagreement that a substance that is increasingly consumed like such should be checked for potential harmful effects on human health and despite MSG's unique taste and appetite enhancement, many studies reported multiple toxic effects at different consumptive levels to both human and experimental animals. 
Our study was performed on pregnant female albino rats and their pups. A period of two weeks treatment of the pregnant rats with a dose of $10 \mathrm{mg} / \mathrm{g}$ body weight revealed a significant increase in the body weight of both the mothers and the pups with a mean difference of about $30 \mathrm{~g}$ in the case of the mothers and almost $1.6 \mathrm{~g}$ in case of the pups, and there was a significant decrease in the weight of the adrenal gland of both mothers and pups with a mean difference of $6.6 \mathrm{mg}$ between the control and treated mothers and 0.8 between the control and treated pups.

Obesity after MSG treatment was a common outcome of many studies. A study conducted in Tanta university on a total of 40 male albino rats aged 4 weeks, receiving an oral dose of $4 \mathrm{mg} / \mathrm{g}$ B.W for 2 weeks showed an analogue observation with a highly significant increase in the total body weight of the treated rats in contrast to the control (4).

Accordingto a previous study, they reported that obesity with increased adiposity index and Lee's index in 10 weeks old rats subcutaneously treated with $4 \mathrm{~g} / \mathrm{kg}$ body weight MSG from day 2 to 14 after birth, other characteristics observed were the accumulation of a great amount of body fat, raised serum leptin, blood glucose, insulin, and lipids(15).

In a cross-sectional study conducted on randomly sampled healthy Chinese, $82.4 \%$ of them used MSG with an average intake of $0.33 \mathrm{~g} /$ day. Results showed that MSG users had a higher BMI and a higher likelihood of being overweight. Also, MSG users have had lower intakes of vegetable protein, total carbohydrates, fibres, starch, and magnesium than nonusers, and higher intakes of animal protein, lipids, cholesterol, and calories. Furthermore, with adjustment for possible confounders, MSG consumption was positively related to BMI. With a $1 \mathrm{~g}$ increase in MSG consumption, BMI increased by $0.61 \mathrm{~kg} / \mathrm{m} 2$. $(\mathrm{P}=0.08)(16)$.

In search of the cause, a previous experiment attributed MSGinduced obesity to the elevated levels of glucagon and insulin, leading to overeating. Another important finding was the decreased serum growth hormone level causing stunted linear growth in neonatal mice (17).

Another study reported that the hypothalamus does not have an impermeable blood-brain-barrier (BBB). Thus, glutamic acid from food can reach the hypothalamus, injuring its neurons (18).

In line with our study, it was reported that MSG-induced obesity in neonatal mice that was of early-onset due to MSGinduced lesions in the arcuate nucleus and that the mice had hyperinsulinemia, hyperleptinemia with dramatically increased fat to bodyweight ratio(19\&20).

In the same line another study also stated that chronic MSG consumption may intoxicate the arcuate nucleus neurons and damage the hypothalamic signaling cascade of leptin action, leading to leptin resistance associated with overweight/obesity(21) . Leptin is an appetite-repressing hormone secreted by fat cells which regulate energy and control appetite and body weight. Although higher size of adipose tissue causes high plasma leptin concentrations, this elevated leptin signal does not provoke the expected satiety response suggesting a developed resistance (22). In our study much adipose tissue was noticed within the greater omentum and behind the peritoneum of the MSG-treated rats.

In contrast to our results, different study stated that there was no significant difference in body weight between control and MSG-treated rats through the course of the experiment(23). Furthermore, , another research reported that the rats that ingested MSG had significantly less weight gain and reduced abdominal fat mass compared to the rats that ingested only water. Also, lower plasma leptin levels were observed(24). However, another study showed that prolonged administration of MSG caused an initial increase in weight gain up till the 4th week in the treated group followed by terminal suppression, despite increased food consumption. He attributed this to the induced gastric mucosal damage observed in the study with subsequent defective digestion and absorption(25).

In agreement with our results regarding the weight of the adrenal gland, it was reported that the weights of the thyroid and adrenal glands of both genders and their gonadal weights were significantly reduced from those of control rats upon autopsy of a MSG neonatally treated rats(26).

Regarding the biochemical study, the present work revealed that MSG treated group had significant decreased corticosterone levels than the control group with a mean difference of $0.3 \mu \mathrm{g} / \mathrm{dl}$.

In agreement with our results ( it was reported that, corticosterone release from the gland decreased in chronic MSG administration and explained that decrease due to the over stimulated hypothalamus by the excess accumulated glutamate with corticotropic releasing factor (CRF) hypersecretion and subsequent down regulation of the pituitary $\mathrm{CRF}$ receptor and decreased adrenocorticotrophic hormone (ACTH) release(11). Furthermore, observations in the rat adrenal showed that steroidogenic activity of the gland was directly influenced by the gland architecture (27).

However, there was controversial researchs showing that the plasma corticosterone level in MSG treated rats had increased in spite of the reduction of the size of the adrenals, which resulted in Cushing's obesity with subsequent salt and water retention. They ascribed that increase to the lower corticosterone degradation rate in the liver slices of rats treated neonatally with MSG(28\&29).

In the current study, microscopical examination of the adrenal cortex in the rats treated with MSG and their pups revealed obvious changes. H\&E-stained sections of the adrenal cortex of the mothers showed a preserved general order of the gland zones with distorted zonal architecture, decreased capsular thickness and increased thickness of the ZF as compared with the control group. Some cells appeared swollen with highly vacuolated cytoplasm. Some had karyolitic nuclei, whereas others lost their nuclei. Some cells partially lost their cellular membranes and a syncytium was formed between them. Most of the changes observed were cortical in particular yet interstitial hemorrhage was noticed to involve the whole gland. 
These results are analogue with a previous study, that reported that, besides the obesity observed in the MSG-treated rats, the most important morphological finding was the widened cortex that is composed mainly of fasciculata cells with abundant and large intracytoplasmic lipid droplets(4).

In the study of the H\&E stained sections of the pups showed that the gland zonation was almost established. On the other hand, the sections of the pups of the treated mothers showed areas of cellular shedding.

This section of the study is unique, yet with a research that reported a number of developmental and behavioral changes in rat offspring that were exposed to MSG in the drinking water during the second and third trimesters of pregnancy, juvenile obesity, decreased general activity levels, and a particular form of learning disability were the key effects observed in MSGtreated offspring (13)

Masson's Trichrome stained sections showed apparent decrease in the capsular collagen fibers with irregular trabeculation in the MSG treated mothers and their pups in contrast to the thick regular fibers of the control group. In addition to separation of the gland capsule in some areas of the MSG treated group. The capsular thinning could be explained by the gland swelling that was followed by terminal shrinkage casing the separation in the gland capsulethat occurred.

Thinning of the adrenal capsule in MSG treated rats was also noticed by a study conducted in Ain Shams University and they further confirmed this by the morphometric results that showed highly statistically significant thinning in the thickness of the adrenal capsule of MSG group in comparison with that of the control group(30).

A previous study have settled that adrenal's functional zonation results from direct lineage conversion between terminally differentiated cells with centripetal migration and concomitant differentiation, during both postnatal development and during regeneration, so adrenal maintenance requires conversion of $\mathrm{ZG}$ cells into ZF cells(31). Furthermore, it was reported that the adrenal capsule acts as a signaling center that controls this cortical renewal and ensures replacement of the damaged cells and thus it's needed to maintain zonation throughout life(32).

Moreover, in the study of the extracellular matrix components and its effect on the gland development, renewal and functioning, iy was reported that the components of the extracellular matrix as collagen IV which was expressed evenly throughout the fetal adrenal gland, and both fibronectin and laminin that demonstrated a mirror-imaged distribution, with laminin more at the periphery of the gland and fibronectin in the central portion (33). Also it was established that when human fetal adrenal cells were cultured on collagen-coated dishes, laminin and fibronectin, Collagen IV and laminin enhanced proliferation whereas fibronectin increased cell death (34). Moreover, another study suggested that centripedal migration of the cells of the adrenal is driven by the extracellular matrix components including collagen, and that the extracellular matrix and the signaling hormones as Angiotensin II and ACTH are noteworthy interconnected and share common pathways involved in adrenal gland activity regulation (35).
Regarding the ultrastructural examination of the adrenal gland of the treated mothers in this study it revealed different degenerative stages in the cortical cells with shrunken, indented and pyknotic nuclei. Increase in the lipid deposition throughout the cytoplasm. Degenerated mitochondria with disrupted cristae and even mitochondria with lipid like inclusions and penetration of the lipid droplets to form "myelin-like" structures were noticed. Disturbed cellular junction, necrotic cells and hemorrhage were also noticed. The medullary cells appeared less affected but apparent increase in the chromaffin granules was noticed.

In this study, ultrastructural examination of adrenal sections of group II pups showed that the cells had euchromatic nuclei with decreased heterochromatin material, or shrunken nuclei with irregular or indented nuclear envelope. Disrupted mitochondria and obvious increase in the secretory material of the cells. Areas of hemorrhage with presence of erythroblasts within the gland. Binucleated cells were also noticed.

These ultrastructural observations are analogous with the results of previous studies using ultrastructural examination of the $\mathrm{ZF}$ of MSG treated rats, revealed that some cells had shrunken nuclei surrounded by a perinuclear electron lucent zone. The cytoplasm showed numerous lipid droplets of variable size; some were full of secretory material and others exhibited marked depletion of secretory material(4) . Also, confluent lipid droplets were noticed. Higher magnifications showed dilated smooth endoplasmic reticulum and swollen mitochondria with disrupted cristae and vesicles inside.

Hemorrhagic areas were reported in different organs of rats treated with MSG was in the same studies reported Extensive areas of hemorrhage among liver parenchyma of MSG orally treated rats(36). Also with a study reported Hemorrhages in the pancreatic islets(37). And according to another study, MSG induced ovarian medullary internal hemorrhage(38). More over another research reported that MSG resulted in infertility via triggering testicular hemorrhage and inhibition of spermatogenesis in male rats(39). It was reported that gross hemorrhage in the rat testis in addition to histological necrotic cells of the different levels of spermatogenesis with pyknotic nuclei.

In reviewing the relation between steroidogenesis and lipid droplets in adrenocortical cells, it was reported that Concomitant decrease in the lipid droplets number and size with the increase in the amount of corticosterone produced by adrenal cells(40). A previous study Explained that the secretory depletion indicated increased secretion with consequent increase in plasma cortisol level, so, it was not strange to find this obvious increase in the lipid droplets with simultaneous low corticosterone level (41).

Regarding the chromaffin granules of the medullary cells, in TEM, the difference in appearance between epinephrine and norepinephrine, after glutaraldehyde fixation, was explained by the hypothesis that most of the epinephrine dissolved, whereas norepinephrine precipitated in situ(42). The apparent concentration of electron-dense material in one part of the granule may be the result of the content shrinkage away from the membranous envelope or to expansion and deformation of the membrane without overall change in the diameter of the 
content, or to a combination of both factors. However, it is artificially produced by the interaction between glutaraldehyde and norepinephrine because it is observed only in granules fixed in glutaraldehyde (43). In this study, the apparent increase in the electron-dense material both in the treated mothers and their pups is likely to be associated with medullary insufficiency.Indeed, ( it was reported that in the MSG model, obesity status was associated with a defective function of the adrenal chromaffin cell with low total catecholamine(44).

As for the binucleation noticed in the treated group, it was stated three mechanisms of binucleate cell production have been reported, either mitotic division without cytokinesis, which is a common process in hepatocytes, nuclear fusion, or amitotic nuclear division which is hypothesized to produce binucleate cells in the palatine mucosa(45). The study also mentioned that in studies of the adrenal glands in mammals using specific stimuli of the glomerular or fascicular region, the presence of binucleate cells has not been exhibited. However, the phenomena of amitosis have been linked with the functioning of the adrenal cortex(45) .

Another study stated an increase in the amitotic divisions of the frog's adrenal cortex following stimulation with ACTH. Therefore, this type of division can be considered important in the set of morphological markers indicating that the cortical region is under feedback stimulation that could be secondary to the decreased serum corticosterone found in this study(46).

\section{REFRENCES}

[1]Yamaguchi, S., and Ninomiya, K. (1998). What is umami? Food Reviews International, 14(2-3), 123-138.

[2] Rolls, E. T. (2009). Functional neuroimaging of umami taste: what makes umami pleasant? The American journal of clinical nutrition, 90(3), 804S-813S.

[3] Park, E., Yu, K. H., Kim, D. K., Kim, S., Sapkota, K., Kim, S.-J., . . Chun, H. S. (2014). Protective effects of N-acetylcysteine against monosodium glutamate-induced astrocytic cell death. Food and chemical toxicology, 67, 1-9.

[4] El-Helbawy, N. F., Radwan, D. A., Salem, M. F., and El-Sawaf, M. E. (2017). Effect of monosodium glutamate on body weight and the histological structure of the zona fasciculata of the adrenal cortex in young male albino rats. Tanta medical journal, 45(2), 104.

[5] Alalwani, A. D. (2014). Monosodium glutamate induced testicular lesions in rats (histological study). Middle East Fertility Society Journal, 19(4), 274-280.

[6]Freeman, M. (2006). Reconsidering the effects of monosodium glutamate: a literature review. Journal of the American Academy of Nurse Practitioners, 18(10), 482-486.

[7] Eweka, A., and Om'Iniabohs, F. (2007). Histological studies of the effects of monosodium glutamate on the cerebellum of adult Wistar rats. Internet J Neurol, 8(1).

[8] Falalyeyeva, T., Leschenko, I., Shevchuk, V., and Beregova, T. (2012). About the influence of long-term injection of monosodium glutamate on pancreas in rats: 17. European Journal of Clinical Investigation, 42.

[9] Nakanishi, Y., Tsuneyama, K., Fujimoto, M., Salunga, T. L., Nomoto, K., An, J.-L., and Suzuki, W. (2008). Monosodium glutamate (MSG): a villain and promoter of liver inflammation and dysplasia. Journal of autoimmunity, 30(1-2), 42-50.

[10] Onaolapo, A. Y., Onaolapo, O. J., Mosaku, T. J., Akanji, O. O., and Abiodun, O. (2013). A histological study of the hepatic and renal effects of subchronic low dose oral monosodium glutamate in Swiss albino mice. Journal of Advances in Medicine and Medical Research, 294-306.
[11] Seo, H. J., Ham, H. D., Jin, H. Y., Lee, W. H., Hwang, H. S., Park, S. A., $\ldots$ and Kim, B. S. (2010). Chronic Administration of Monosodium Glutamate under Chronic Variable Stress Impaired Hypothalamic-Pituitary-Adrenal Axis Function in Rats. The Korean Journal of Physiology and Pharmacology, 14(4), 213-221.

[12] Diemen V.V.. and Trindade M. R.M.(2010): Effect of the oral administration of monosodium glutamate during pregnancy and breastfeeding in the offspring of pregnant Wistar rats. Acta Cir. Bras. 25 (1). [13] Chakraborty S P. (2019): Patho-physiological and toxicological aspects of monosodium glutamate. Toxicology mechanisms and methods , 29(6), 389-396.

[14] Clayden, E. C. (2000)). Practical section cutting and staining. Churchill Livingstone. Edinburgh and London.

[15]Kumar, P., and Bhandari, U. (2016). Fenugreek seed extract prevents fat deposition in monosodium glutamate (MSG)-obese rats. Drug research, 66(04), 174-180.

[16] He, K., Zhao, L., Daviglus, M. L., Dyer, A. R., Van Horn, L., Garside, D., ... and Stamler, J. (2008). Association of monosodium glutamate intake with overweight in Chinese adults: the INTERMAP Study. Obesity, 16(8), 1875-1880.

[17] Hermanussen, M., Garcia, A. P., Sunder, M., Voigt, M., Salazar, V., and Tresguerres, J. A. F. (2006). Obesity, voracity, and short stature: the impact of glutamate on the regulation of appetite. European journal of clinical nutrition, 60(1), 25-31.

[18]Hawkins, R. A. (2009). The blood-brain barrier and glutamate. The American journal of clinical nutrition, $90(3), 867 \mathrm{~S}-874 \mathrm{~S}$.

[19] Cekić, S., Filipović, M., Pavlović, V., Ćirić, M., Nešić, M., Jović, Z., and Branković, S. (2005). Histopathologic changes at the hypothalamic, adrenal and thymic nucleus arcuatus in rats treated with monosodium glutamate. Acta medica medianae, 44(3), 35-42.

[20] Matysková, R., Maletinska, L., Maixnerová, J., Pirnik, Z., Kiss, A., and Zelezna, B. (2008). Comparison of the obesity phenotypes related to monosodium glutamate effect on arcuate nucleus and/or the high fat diet feeding in C57BL/6 and NMRI mice. Physiological research, 57(5), 727.

[21]Hermanussen, M., and Tresguerres, J. A. F. (2003). Does high glutamate intake cause obesity?. Journal of Pediatric Endocrinology and Metabolism, 16(7), 965-968.

[22]Jequier, E. (2002). Leptin signaling, adiposity, and energy balance. Annals of the New York Academy of Sciences, 967(1), 379-388.

[23]Miskowiak, B., and Partyka, M. (1993). Effects of neonatal treatment with MSG (monosodium glutamate) on hypothalamopituitary-thyroid axis in adult male rats. Histology and histopathology. [24]Merrett N. (2008). MSG may reduce body weight again, Ajinomoto study; Available at: https://www.foodnavigatorusa.com/Article/2008/ 10/15/ MSG-may-reduce-body-weight-gainAjinomoto-study.

[25]Abd El-Aziz, G. S., El-Fark, M. O., Hassan, S. M., and Badawoud, M. H. (2014). Effects of prolonged oral intake of monosodium glutamate (MSG) on body weight and its correlation to stomach histopathological changes in male rats. The Thai Journal of Veterinary Medicine, 44(2), 201.

[26]Redding, T. W., Schally, A. V., Arimura, A., and Wakabayashi, I. (1971). Effect of monosodium glutamate on some endocrine functions. Neuroendocrinology, 8(3-4), 245-255.

[27]Carsia, R. V., Tilly, K. I., and Tilly, J. L. (1997). Hormonal modulation of apoptosis in the rat adrenal gland in vitro is dependent on structural integrity. Endocrine, 7(3), 377-381.

[28]Magariños, M., Estivariz, F., Morado, I., and De Nicola, A. F. (1988). Regulation of the central nervous system-pituitary-adrenal axis in rats after neonatal treatment with monosodium glutamate. Neuroendocrinology, 48(2), 105-111.

[29] Macho, L., Jezova, D., Zorad, S., and Fickova, M. (1999). Postnatal monosodium glutamate treatment results in attenuation of corticosterone metabolic rate in adult rats. Endocrine regulations, 33, 61-68.

[30]Bekheet, E. A., and Shokry, M. M. (2020). The possible protective role of vitamin $\mathrm{C}$ against Monosodium glutamate induced structural changes of adrenal cortex of the adult male albino rat: Histological and 
immunohistochemical study. Egyptian Journal of Histology, 43(1), 160-172.

[31]Freedman, B. D., Kempna, P. B., Carlone, D. L., Shah, M. S., Guagliardo, N. A., Barrett, P. Q., ... and Breault, D. T. (2013). Adrenocortical zonation results from lineage conversion of differentiated zona glomerulosa cells. Developmental cell, 26(6), 666673.

[32]Vidal, V., Sacco, S., Rocha, A. S., da Silva, F., Panzolini, C., Dumontet, T., and Schedl, A. (2016). The adrenal capsule is a signaling center controlling cell renewal and zonation through Rspo3. Genes and development, 30(12), 1389-1394.

[33]Chamoux, E., Bolduc, L., Lehoux, J. G., and Gallo-Payet, N. (2001). Identification of extracellular matrix components and their integrin receptors in the human fetal adrenal gland. The Journal of Clinical Endocrinology and Metabolism, 86(5), 2090-2098.

[34]Chamoux, E., Narcy, A., Lehoux, J. G., and Gallo-Payet, N. (2002). Fibronectin, laminin, and collagen IV as modulators of cell behavior during adrenal gland development in the human fetus. The Journal of Clinical Endocrinology and Metabolism, 87(4), 1819-1828.

[35]Chamoux, E., Otis, M., and Gallo-Payet, N. (2005). A connection between extracellular matrix and hormonal signals during the development of the human fetal adrenal gland. Brazilian journal of medical and biological research, 38(10), 1495-1503.

[36]Elbassuoni, E. A., Ragy, M. M., \& Ahmed, S. M. (2018). Evidence of the protective effect of 1-arginine and vitamin D against monosodium glutamate-induced liver and kidney dysfunction in rats. Biomedicine \& Pharmacotherapy, 108, 799-808.

[37]Boonnate, P., Waraasawapati, S., Hipkaeo, W., Pethlert, S., Sharma, A., Selmi, C., ... \&Cha'on, U. (2015). Monosodium glutamate dietary consumption decreases pancreatic $\beta$-cell mass in adult Wistar rats. PLoS One, 10(6), e0131595.

[38]El-Beltagy, A. E. F., \&Elghaweet, H. A. (2016). Adverse effects of monosodium glutamate on the reproductive organs of adult Female albino rats and the possible ameliorated role of carob (Ceratonia Siliqua). Journal of Bioscience and Applied Research, 2(3), 170-184.

[39] Oforofuo, I. A. O., Onakewhor, J. U. E., \&Idaewor, P. E. (1997). The effect of chronic administration of MSG on the histology of the adult Wistar rat testes. Bio Res Comm, 9(2), 30-56.

[40]Wang, S. M., Lee, L. J., Lin, W. W., \& Chang, C. M. (1998). Effects of a water- soluble extract of Cordyceps sinensis on steroidogenesis and capsular morphology of lipid droplets in cultured rat adrenocortical cells. Journal of cellular biochemistry, 69(4), 483489.

[41]Szabó, D., Czakó, F., Tóth, I. E., Szalay, K. S., Krasznai, K., \& Stark, E. (1992). Effect of chronic ACTH treatment on the physical state of lipid droplets in rat adrenocortical cells. The Journal of steroid biochemistry and molecular biology, 41(3-8), 781-784.

[42]Kobayashi, S., and Coupland, R. E. (1993). Morphological aspects of chromaffin tissue: the differential fixation of adrenaline and noradrenaline. Journal of anatomy, 183 ( Pt 2)(Pt 2), 223-235.

[43]Coupland, R. E. (1965). Electron microscopic observations on the structure of the rat adrenal medulla: I. The ultrastructure and organization of chromaffin cells in the normal adrenal medulla. Journal of anatomy, 99(Pt 2), 231.

[44]Martins, A. C., Souza, K. L., Shio, M. T., Mathias, P. C., Lelkes, P. I., \& Garcia, R. M. (2004). Adrenal medullary function and expression of catecholamine-synthesizing enzymes in mice with hypothalamic obesity. Life sciences, 74(26), 3211-3222.

[45]Palacios, G., Lafarga, M., \& Perez, R. (1976). Ultrastructural study of binucleation in cells of the rat adrenal glomerular zone after a prolonged low-sodium diet. Experientia, 32(7), 909-911.

[46]Leist, K. H., Bergerhoff, K., Pehlemann, F. W., \& Hanke, W. (1968). Histophysiologische Untersuchungen der Entwicklung des Interrenalorgans beim Krallenfrosch (Xenopus laevisDaudin). Cell and Tissue Research, 93(1), 105-125. 